\title{
The Effects of Some Hormone Applications on Lilium martagon L. Germination and Morpholgical Characters
}

\author{
Kerim Guney$^{1}$, Mehmet Cetin ${ }^{2 *}$, Kudret Betul Guney ${ }^{3}$, Abdullah Melekoglu ${ }^{4}$ \\ ${ }^{1}$ Kastamonu University, Faculty of Forestry, Department of Forest Engineering, Kuzeykent, Kastamonu, Turkey \\ ${ }^{2}$ Kastamonu University, Faculty of Engineering and Architecture, Department of Landscape Architecture, \\ Kuzeykent, Kastamonu, Turkey \\ ${ }^{3}$ Ankara University, Graduate School of Natural and Applied Science, Ankara, Turkey \\ ${ }^{4}$ Kastamonu University, Faculty of Engineering and Architecture, Department of Genetics and Bioengineering, \\ Kuzeykent, Kastamonu, Turkey
}

Received: 11 April 2017

Accepted: 3 May 2017

\begin{abstract}
Lilium martagon L. is a perennial geophyte species belonging to the large Liliaceae family. Its population is at the status of "VU" in the Red Data Book of Turkish Plants, and along with many European countries, it is included in Turkey's list of plants that are endemic and imperiled. This study analyzed the potential of producing Lilium martagon L. with teeth. Four different hormones (IAA: iIndole-3-acetic acid; IBA: indole-3-butyric acid; NAA: naphthylacetic acid; and GA3: gibberellic acid) were applied in three doses $(1,000,3,000$, and 5,000 ppm) on apical, medium, and basal parts and after 120 days, six morphological characteristics were determined. According to the results, 1,000 ppm IBA implementation is seen as the most effective hormone dose implementation on morphological characters. According to the effect of fraction position, for all characters the individuals formed by the pieces taken from the bottom parts of teeth are included in the first homogeneous group. Also, it is revealed that each of the apical, medium, and basal parts were obtained by cutting nail-like scales on the corpus in three equal pieces and have the potential for meristematic reproduction ability.
\end{abstract}

Keywords: Lilium martagon L., hormone, onion scales, germination, morphological characters

\section{Introduction}

Lilium belongs to the Lilieae tribe of Liliaceae and contains about 120 species [1]. Lily is one of the most important horticultural plants and many wild species and

*e-mail: mcetin@kastamonu.edu.tr cultivars have been cultivated for bulb and cut-flower production [2].

Lilium martagon L. is a perennial geophyte species belonging to the large Liliaceae family. Its population holds VU status in the Red Data Book of Turkish Plants, and along with many European countries, it is included in Turkey's list of the plants that are endemic and imperiled. Lilium martagon L., referred to as "Turks Cap" outside of Turkey, draws attention with its ostentatious flower 
situation and its tendency to be produced for cut flowers. Lilium onions consist of fat-grown scaly leaves attached to basal plaque.

The basic aim of this research is to determine the production potential in pieces belonging to subsoil organs of the Lilium martagon L. plant whose generation status is "under the risk of damage."

\section{Material and Methods}

The onions belonging to Lilium martagon L. used in research were gathered from Küre Mountains National Park Ilica site. The onions gathered 10-11 July were preserved by being moistened in germination peat. The implementations on the onions brought to laboratory were practiced on 13 July as such:

1. $2 / 3$ of the $3 \times 3-15 \mathrm{~cm}$. polyethylene tubes in laboratory were prepared by being filled with germination peat of the brand Klassman.

2. The pleas constituting onions were separated by cutting basal parts with a sterile lancet. The nail-like pleas were divided into three parts, as each of their apical, medium, and basal parts are equal.

3. These three different parts obtained from nail-like pleas were put to three solutions in different doses $(1,000$, 3,000 , and 5,000 ppm) and 13 implementation groups $(3 \times 4=12+1($ control $)=13)$ were constituted. The list of hormones and doses applied are given below:

a) 1,000 ppm indole-3-acetic acid

b) 1,000 ppm indole-3-butyric acid

c) 1,000 ppm gibberellic acid

d) 1,000 ppm naphthylacetic acid

e) 3,000 ppm indole-3-acetic acid

f) 3,000 ppm indole-3-butyric acid

g) 3,000 ppm gibberellic acid

h) 3,000 ppm naphthylacetic acid

i) 5,000 ppm indole-3-acetic acid

j) 5,000 ppm indole-3-butyric acid

k) 5,000 ppm gibberellic acid

1) 5,000 ppm naphthylacetic acid

m) Control

The implementations were carried out by sinking samples to the hormone for 3-5 seconds. This implementation was arranged as three repeats and 15 samples in each repeat (15 apical, 15 basal, 15 medium). The prepared tubes were placed with care not to let them contact each other, 15 pieces were placed in each tubes, their surface was covered with more or less $2 \mathrm{~cm}$ germination peat, and they were moistened immediately.

1. These tubes were placed in perforated boxes at $20-25^{\circ} \mathrm{C}$ room temperature and not exposed to sunlight, and they were watered every other day for 120 days. The peat reached the overload point while watering, puddles were not occurring in tubes since the tubes and the boxes they are placed in are perforated, and excess water was moved away by flowing.

2. Measurements were performed 10 November (day 120). During this, peat was poured on the bench, roots were cleaned carefully, and root number was determined and then the average height of the roots was measured with a micro compass. After that, each sample was washed with water and child root number was determined, and child roots height and caliber were measured. All of the measurements were made with a digital micro compass with the sensitivity of $0.01 \mathrm{~mm}$, and obtained results were presented on a prepared table. Thus six characteristics were determined at the end of the study, namely: germination percentage (GP), number of roots (RN), root height (RH), child corpus height $(\mathrm{CCH})$, child corpus caliber (CCC), and child corpus number $(\mathrm{CCN})$.

3. SPSS 17.0 package program's variance analysis was implemented on this data, Duncan test was made for characters that have statistically at least 95\% differences in trust level, and homogeneous groups were obtained and interpreted.

\section{Results and Discussion}

In consequence of the research, rooting percentage of hormone implementations, nascent child corpus number, root number, root height, child corpus height, child corpus caliber, and their effect on root height were analyzed with the help of SPSS package program, and average value of determined characters, variance analysis, and results of the Duncan test are presented in Table 1.

When table values are analyzed, it is observable that its effect on rooting percentage of hormone implementations and root numbers is at $95 \%$, and on child corpus number it is at $99.9 \%$ trust level. With the aim of determining the effects of $\mathrm{x}$ dose contamination on rooting percentage and morphological features of nascent individuals, each hormone dose implementation is accepted as a separate implementation and the obtained data was analyzed. As a result of the statistical evaluation, the effect of hormone $\mathrm{x}$ dose contamination on rooting percentage and child corpus height is found to be meaningless statistically, while it is found that its effect is meaningful on root height and root number at $99 \%$, and on child corpus number and child corpus caliber at $99.9 \%$ trust level. The obtained results, variance analysis implemented on this data, and results of Duncan test are presented in Table 2.

When table values are analyzed, it is observable that the control group is included in the first homogeneous group in terms of all characters. This situation shows that while hormone implementations do not affect rooting percentage, it considerably affects nascent individuals' morphological characters. 1,000 ppm IBA implementation is seen as the most effective hormone dose implementation on morphological characters, and in terms of root number and child corpus caliber, the highest values are obtained as a result of this implementation. The values obtained from child individuals formed as a result of 1,000 ppm IBA implementation are included in the last homogeneous groups in terms of other characters according to Duncan test results, and these results show that 1,000 ppm IBA 
Table 1. Germination percentage of hormone implementations and its effect on morphologic characters.

\begin{tabular}{|c|c|c|c|c|c|c|c|c|c|}
\hline Hormone & GP & & RN & & CCN & & CCH & CCC & RH \\
\hline IAA & 62.39 & $\mathrm{~b}$ & 1.68 & $\mathrm{~b}$ & 1.34 & $\mathrm{a}$ & 10 & 2.68 & 90.42 \\
\hline IBA & 36.92 & $\mathrm{ab}$ & 2.11 & $\mathrm{~b}$ & 2.04 & $\mathrm{~b}$ & 6.6 & 2.49 & 53.37 \\
\hline GA3 & 29.23 & $\mathrm{a}$ & 1.62 & $\mathrm{~b}$ & 1.24 & $\mathrm{a}$ & 6.1 & 2.79 & 79.08 \\
\hline NAA & 49.57 & $\mathrm{ab}$ & 2.03 & $\mathrm{~b}$ & 1.5 & $\mathrm{a}$ & 5.74 & 2.43 & 50.26 \\
\hline Cont. & 23.08 & $\mathrm{a}$ & 0.78 & $\mathrm{a}$ & 1.11 & $\mathrm{a}$ & 5.41 & 1.49 & 48.49 \\
\hline F Value & $2.760^{*}$ & & $3.048^{*}$ & & $8.791^{* * *}$ & & $2.046 \mathrm{~ns}$ & $2.074 \mathrm{~ns}$ & $1.388 \mathrm{~ns}$ \\
\hline
\end{tabular}

*significant at 0.05 level, $* * *$ significant at 0.001 level, ns: not significant

GP: Germination percentage; RN: Number of roots; CCN: Child corpus number; $\mathrm{CCH}$ : Child corpus height; CCC: Child corpus caliber; RH: Root height

IAA: Indole-3-acetic acid; IBA: Indole-3-butyric acid; GA3: Gibberellic acid; NAA: Naphthylacetic acid

implementation affects morphological characters of child corpuses positively. Child corpuses formed as a result of this implementation are developed 80\% numerically, $60 \%$ in terms of height, $120 \%$ in diameter more than control group, the roots of these corpuses are $60 \%$ longer, and $250 \%$ more in terms of number than the control group. The most efficient implementation on child corpus number is 5,000 ppm NAA implementation. As a result of this implementation, an average of 2.17 child corpuses are formed in individuals while it is 1.11 in control group. However, when average values are analyzed, it is observed that IBA hormone implementation has the highest average. Child corpus number is above 2 in individuals who pass through this implementation is made. The individuals who pass through the 3,000 ppm IAA implementation has the highest root development as a result of the study, and the roots of the individuals who pass through this implementation are more than three times higher than the control group individuals who did not pass through any implementation. With the aim of presenting meristematic ability of different parts of metamorphic subsoil corpus pieces, new individual forming rates of the parts that are obtained by cutting apical, medium, and basal parts of the nail-like scales in three equal pieces and morphological characters of the formed individuals are determined. The average values of obtained data, F-value obtained as a

Table 2. The effect of hormone $\mathrm{x}$ dose contamination on morphological characters.

\begin{tabular}{|c|c|c|c|c|c|c|c|c|c|c|}
\hline Hor. & Dose & $\mathbf{R N}$ & & $\mathrm{CCN}$ & & $\mathrm{CCH}$ & $\mathrm{CCC}$ & & RH & \\
\hline IAA & 5000 & 1.8 & abcde & 1.56 & abcd & 7.41 & 1.74 & $a b$ & 53.17 & $\mathrm{a}$ \\
\hline IBA & 5000 & 1.23 & $a b$ & 2.08 & $\mathrm{~cd}$ & 5.41 & 1.92 & $a b c$ & 30.22 & $\mathrm{a}$ \\
\hline GA3 & 5000 & 1.55 & abcd & 1.5 & $a b c$ & 6.39 & 3.14 & $\mathrm{~d}$ & 95.4 & $a b$ \\
\hline NAA & 5000 & 2.33 & cde & 2.17 & d & 4.8 & 2.31 & abcd & 100.83 & $\mathrm{ab}$ \\
\hline IAA & 3000 & 1.84 & bcde & 1.28 & $\mathrm{ab}$ & 15.22 & 3.33 & d & 157.65 & $\mathrm{~b}$ \\
\hline IBA & 3000 & 2.21 & bcde & 2.05 & cd & 5.81 & 2.25 & abcd & 45.23 & $\mathrm{a}$ \\
\hline GA3 & 3000 & 1.5 & abcd & 0.93 & $\mathrm{a}$ & 5.03 & 2.36 & abcd & 72.34 & $\mathrm{ab}$ \\
\hline NAA & 3000 & 2.43 & de & 1.07 & $a b$ & 5.87 & 2.21 & abcd & 43.79 & $\mathrm{a}$ \\
\hline IAA & 1000 & 1.39 & abcd & 1.17 & $\mathrm{ab}$ & 7.13 & 3 & cd & 59.08 & $\mathrm{a}$ \\
\hline IBA & 1000 & 2.73 & $\mathrm{e}$ & 2 & $\mathrm{~cd}$ & 8.63 & 3.29 & $\mathrm{~d}$ & 75.95 & $a b$ \\
\hline GA3 & 1000 & 1.77 & abcde & 1.18 & $a b$ & 6.48 & 2.72 & bcd & 69.6 & $a b$ \\
\hline NAA & 1000 & 1.3 & $\mathrm{abc}$ & 1.7 & bcd & 6.12 & 2.8 & bcd & 25.25 & $\mathrm{a}$ \\
\hline Cont. & 0 & 0.78 & $\mathrm{a}$ & 1.11 & $\mathrm{ab}$ & 5.41 & 1.49 & $\mathrm{a}$ & 48.49 & $\mathrm{a}$ \\
\hline F Val. & & $2.730 * *$ & & $4.638 * * *$ & & $1.794 \mathrm{~ns}$ & $3.749 * * *$ & & $2.326^{* *}$ & \\
\hline
\end{tabular}

*significant at 0.05 level, ${ }^{* * *}$ significant at 0.001 level, ns: not significant

GP: Germination percentage; RN: Number of roots; CCN: Child corpus number; CCH: Child corpus height; CCC: Child corpus caliber; RH: Root height

IAA: Indole-3-acetic acid; IBA: Indole-3-butyric acid; GA3: Gibberellic acid; NAA: Naphthylacetic acid 
Table 3. Effect of fraction position.

\begin{tabular}{|c|c|c|c|c|c|c|c|c|c|c|c|c|}
\hline Position & \multicolumn{2}{|c|}{ GP } & \multicolumn{2}{c|}{ RN } & \multicolumn{2}{c|}{ CCN } & \multicolumn{2}{c|}{ CCH } & \multicolumn{2}{c|}{ CCC } & \multicolumn{2}{c|}{ RH } \\
\hline Basal & 65.74 & $\mathrm{a}$ & 2.27 & $\mathrm{a}$ & 1.44 & $\mathrm{a}$ & 9.92 & $\mathrm{a}$ & 3.3 & $\mathrm{a}$ & 104.67 & $\mathrm{a}$ \\
\hline Medium & 45.39 & $\mathrm{~b}$ & 1.78 & $\mathrm{~b}$ & 1.73 & $\mathrm{~b}$ & 5.84 & $\mathrm{~b}$ & 2.24 & $\mathrm{~b}$ & 46.69 & $\mathrm{~b}$ \\
\hline Apical & 28.85 & $\mathrm{~b}$ & 0.84 & $\mathrm{c}$ & 1.29 & $\mathrm{a}$ & 4.5 & $\mathrm{~b}$ & 1.7 & $\mathrm{c}$ & 33.19 & $\mathrm{~b}$ \\
\hline F Value & \multicolumn{2}{|c|}{$8.194 * *$} & \multicolumn{2}{|c|}{$25.444^{* * *}$} & $4.223^{*}$ & $6.366^{* *}$ & $32.290^{* * *}$ & $10.237^{* * *}$ \\
\hline
\end{tabular}

*significant at 0.05 level, ***significant at 0.001 level, ns: not significant

GP: Germination percentage; RN: Number of roots; CCN: Child corpus number; $\mathrm{CCH}$ : Child corpus height; CCC: Child corpus caliber; RH: Root height

result of variance analysis, and groupings formed as a result of Duncan test are presented in Table 3.

When the table is examined it is seen that apical, medium, and basal parts are effective on all characters of nascent individuals along with rooting percentage, and this effect is statistically meaningful in trust level at $95 \%$ in child corpus number; at $99 \%$ in rooting percentage and child corpus height; and at $99 \%$ in rooting number, child corpus caliber, and rooting height. In terms of rooting percentage (child corpus height and root height), two homogeneous groups are formed as a result of Duncan test, and three homogeneous groups are formed in terms of other characters. In terms of all characters, the individuals formed by the pieces taken from the bottom parts of teeth are included in the first homogeneous group. This situation shows that rooting percentage is considerably higher in basal parts taken from nail, and the individuals formed in these parts are more developed than the individuals formed in other parts in terms of morphological characters. In this research, it is revealed that each of the apical, medium, and basal parts obtained by cutting nail-like scales on the corpus in three equal pieces have potential meristematic reproduction ability. Starting off from this result, it is determined that potential reproduction ability of each Lilium onion is at least three times higher than the number of nail-like scales in the onion. When table values are examined, it is observed that in terms of child corpus number, the highest values are obtained from the pieces taken from the middle parts of the nails. While the pieces taken from the basal parts have the highest values in all characters except for the child corpus number, the pieces taken from the apical part have the lowest values. This shows that meristematic reproduction ability decreases from basal area to apical area. The fact that the basal part is less in number than the middle part in terms of child corpus number results from apical and basal pieces having one cross-section while the middle part has two crosssections, and the meristematic activity occurred in the middle part's edges that are adjacent to both apical and basal surfaces.

There are many studies with regards to the production of Lilium species. Hormone applications were practiced in a certain number of these in-vitro production studies. Bacchetta et al. [3] analyzed the effects of IBA and NAA on Lilium longiflorum; Chen et al. [4] analyzed the effects of NAA, IBA, and NAA on Lilium oritential and Lilium longifolorum; LingFei et al. [5] analyzed the effects of NAA and IBA on Lilium davidii var. unicolor; Han et al. [6] analyzed the effect of BA and IAA on Lilium longiflorum; Yan et al. [7] analysed the effect of IAA, IBA, and NAA on Lilium oritential; Yamagishi [8] analyzed the effect of BA and GA3 on Lilium japonicum; and Jing [9] analyzed the effect of IAA, IBA, and NAA on Lilium davidii var. unicolor.

Guney et al. [10] performed 3 to 4 different doses of hormones in Lilium martagon L. seed, and the results were compared with the control group. In conclusion, IAA 5,000 ppm, 3,000 ppm IAA, and 1,000 ppm NAA application could increase the germination percentage of the approximately three-fold, and they found the effective application of the hormone on root characters.

Guney et al. [11] reported that similar results were also obtained in Lilium artvinense possible seed. It has been effective on all types of hormones, especially in terms of germination. The results showed that the percentage of $40 \%$ germination in the control group raised up to $60.66 \%, 75.34 \%, 82.66 \%$, and $84 \%$ in the seeds consulted with NAA, IAA, IBA, and GA3, in sequence.

Sevik and Turhan [12] studied the effects of the hormone Lilium martagon L. onion mixture and it stated that the study results in the highest percentage of rooting reached 3,000 ppm IBA +100 ppm IAA. Sevik and Cetin [13] Lilium artvinense also stated that if the onion in 3,000 ppm IAA with $28.57 \%$ rise in the percentage of rooting had $80.22 \%$.

Study results are the number of roots $(\mathrm{RN})$, root height $(\mathrm{RH})$, child corpus height $(\mathrm{CCH})$, child corpus caliber (CCC), and child corpus number (CCN) shows the effect that the positive direction in the entire hormone application.

Most of the studies have researched the effect of auxin hormones on rooting and morphological characteristics studied in many species such as Melissa officinalis [14], Robinia pseudoacacia [15], Pseudotsuga menziesii [16], Oryza sativa [17], and Pisum sativum [18].

The findings of the research are done in conformity with the other works in the study area. One set of researchers, Sevik and Turhan 2015 [12], studied that all hormone treatments and raised the number of roots in Lilium martagon L. with 3,000 ppm IBA $+1,000$ ppm NAA treatment. Besides, they emphasized that the average root number in of Lilium artvinense was raised to 2.50 
with $1,000 \mathrm{ppm}$ IBA treatment [13]. Other researchers, like Guney et al. [10], stressed that the root number of Lilium martagon L. seeds were raised up to 2.0 with 3,000 ppm GA3 treatment.

The studies carried out on other plant species also demonstrate that root number can be raised with hormone treatments. Besides, Yildiz [19] informs us that the root number of plum was raised to the average number of 2.3 in the seeds treated with IBA, while Ayanoğlu and Özkan [20] indicated that the root number of Salvia officinalis L. was raised to 22.35 with 100 ppm IBA treatment. Identically, there are researchers conceiving that IBA treatment can raise the number of roots 4 to 5 times in peach, plum, and cherry cuttings [21]. In research by Demiral and Ulger [22], the root number of 4.40 in the control group of cherry cuttings was raised to 16.29 with $6 \mathrm{mg} / \mathrm{l}$ NAA treatment, while conducting in the research by Şevik et al. [23], the average root number of 5.82 in the control group of Schefflera arboricola L. was raised with 1,000 ppm NAA and GA3 treatments, in order.

The highest root lengths were acquired with 3,000 ppm IBA treatment in the study by Turhan [24] on Lilium martagon; in the research by Guney et al. [10] on Lilium martagon L. seeds and in the study by Topacoglu et al. [25] on Ficus benjamina cuttings. The research indicated that the root length can be raised:

2.75 times in Lilium artvinense with 3,000 ppm GA3 treatment [13].

16.17 times in plum cuttings with 2,000 ppm IBA treatment [26].

2.34 times in cherry cuttings with 4,000 ppm IBA treatment [16].

1.63 times in Schefflera arboricola with 1000 ppm IBA treatment [27].

2.26 times in sage with $100 \mathrm{ppm}$ IBA [18], as compared to the control group.

There are many studies on PM sources, PM compounds, PM content, etc. [28-32]. Many studies conducted around the world have revealed that PM2.5 and PM10 concentrations reach critical levels in areas where traffic density is high; however, the studies are limited in many aspects [33-37].

\section{Conclusions}

The results of the study demonstrate that $1,000 \mathrm{ppm}$ IBA implementation is seen as the most effective hormone dose implementation on morphological characters. According to the effect of fraction position, for all characters the individuals formed by the pieces taken from the bottom parts of teeth are included in the first homogeneous group.

According to the results of this study, it is revealed that each of the apical, medium, and basal parts obtained by cutting nail-like scales on the corpus in three equal pieces have potential meristematic reproduction ability. Starting off from this result, it is determined that potential reproduction ability of each Lilium onion is at least three times higher than the number of nail-like scales in an onion.

\section{References}

1. GAO Y.D., HARRIS A.J., ZHOU S.D., HE X.J. Evolutionary events in Lilium (including Nomocharis, Liliaceae) are temporally correlated with orogenies of the Q-T plateau and the Hengduan Mountains. Mol. Phylogenet. Evol, 68, 443, 2013.

2. GODO T., KOBAYASHI K., TAGAMI T., MATSUI K., KIDA T. In vitro propagation utilizing suspension cultures of meristematic nodular cell clumps and chromosome stability of Lilium=formolongi hort, Sci. Hort. 72, 193, 1998.

3. BACCHETTA L., REMOTTI P.C., BERNARDINI C., SACCARDO F. Adventitious shoot regeneration from leaf explants and stem nodes of Lilium, Plant Cell Tiss. Org. $\mathbf{7 4}$ (1), 37, 2003.

4. CHEN L.J., ZHANG X.G., MA S., ZHONG M., GUO Z.F., MING J. Study on the rapid propagation of Lilium oritential and Lilium longifolorum, Northern Horticulture, 2010-14, 2010.

5. LINGFEI X., FENGWANG M., DONG L. Plant regeneration from in vitro cultured leaves of Lanzhou lily (Lilium davidii var. unicolor). Sci. Hort. 119, 458, 2009.

6. HAN B.H., YU H.J., YAE B.W., PEAK K.Y. In vitro micropropagation of Lilium longiflorum 'Georgia' by shoot formation as influenced by addition of liquid medium. Sci. Hort. 103, 39, 2004.

7. YAN F.Y., HU X.Y., PEI X.H., YIN D.S. Effect of hormone on scale propagation of Lilium oriental, Liaoning Agricultural Science, 6, 5, 2008.

8. YAMAGISHI M. Effects of cold treatment, BA and GA3 on enlargement and leaf emergence of in vitro cultured bulblets of Lilium japonicum Thunb. J. Jpn. Soc. Hortic. Sci. 64 (2), 367, 1995.

9. JING L. Optimization of highly efficient plant regeneration system for Lilium davidii var. unicolor (Hoog) cotton., J. Southern Agric. 42 (8), 839, 2011.

10. GÜNEY K., CETIN M., SEVIK H., GUNEY B.K. Influence of germination percentage and morphological properties of some hormones practice on Lilium martagon L. seeds, Oxid. Commun. 39 (1-II), 466, 2016.

11. GÜNEY K., CETIN M., SEVIK H., GUNEY B.K. Chapter title: Effects of Some Hormone Applications on Germination and Morphological Characters of Endangered Plant Species Lilium artvinense L. Seeds, eds Araújo Susana, Balestrazzi Alma, "New Challenges in Seed Biology - Basic and Translational Research Driving Seed Technology" InTech, ISBN:978-953-51-4740-4, 2016.

12. SEVIK H., TURHAN H. Effects of IBA (Indole Butiric Acide) on rooting and newly stem to Turkish Lili (Lilium martagon L.) onion. The international conference on science, ecology and technology I (Iconsete'2015 - Vienna) Abstract Book, p. 61, August 25-28, 2015, Vienna, Austria, 2015.

13. SEVIK H., CETIN M. Effects of some hormone applications on germination and morphological characters of endangered plant species Lilium Artvinense I. Onion Scales. Bulg. Chem. Commun. 2 (48), 256, 2016.

14. SEVIK H., GÜNEY K. Effects of IAA, IBA, NAA, and GA3 on Rooting and Morphological Features of Melissa officinalis L. Stem Cuttings, Scientific World J. 2013, Article ID 909507,5 pages. 2013. 
15. SWAMY S.L., PURI S., SINGH A.K. Effect of auxins (IBA and NAA) and season on rooting of juvenile and mature hardwood cuttings of Robinia pseudoacacia and Grewia optiva. New Forests, 23 (2), 143, 2002.

16. STEFANCIC M., STAMPAR F., OSTERC G. Influence of IAA and IBA on root development and quality of Prunus "GiSelA 5" leafy cuttings. HortScience, 40 (7), 2052, 2005.

17. CHHUN T., TAKETA S., TSURUMI S., ICHII M. The effects of auxin on lateral root initiation and root gravitropism in a lateral rootless mutant Lrt1 of rice (Oryza sativa L.). Plant. Growth. Regul., 39, 161, 2003.

18. NORDSTRÖM A.C., JACOBS F.A., ELIASSON L. Effect of Exogenous Indole-3-Acetic Acid and Indole-3-Butyric Acid on Internal Levels of the Respective Auxins and Their Conjugation with Aspartic Acid during Adventitious Root Formation in Pea Cuttings. Plant Physiol., 96, 856, 1991.

19. YILDIZ K. The effect of IBA, CEPA and AVG on rooting of hardwood cuttings in different fruit species. J. Agr. Sci. YYU, 11 (1), 51, 2001.

20. AYANOĞLU F., ÖZKAN C.F. Change in tissue mineral elemental concentration during root initiation and development of Salvia officinalis L. cuttings and IBA effects. Turk. J. Agric. For. 24, 677, 2000.

21. EDIZER Y., DEMIREL M.A. A study on the some characteristics of rooting of green cuttings of the some clonal rootstock in mist propagation. GOU J. Agric. 29 (2), 1, 2012.

22. DEMIRAL S., ÜLGER S.A. Research on propagation of gisela 5 cherry rootstock by tissue culture. J. Fac. Agric. of Akdeniz University. 21 (1), 117, 2008.

23. SEVIK H., GÜNEY K., TOPAÇOĞLU O., ÜNAL C. The influences of rooting media and hormone applications on rooting percentage and some root characters in Schefflera Arboricola. Int. J Pharm Sci Invent. 4 (2), 25, 2015.

24. TURHAN H. Effects of IBA (indole butiric acide) on rooting and newly stem to Turkish lili (Lilium martagon L.) onion [thesis]. Graduate School of Natural and Applied Sciences Department of Forest Engineering: Kastamonu Univesity; MsC Thesis, 201552 p., 2016.

25. TOPACOGLU O., SEVIK H., GUNEY K., UNAL C., AKKUZU E., SIVACIOGLU A. Effect of rooting hormones on the rooting capability of Ficus benjamina L. cuttings. Sumarski List. 140 (1-2), 39, 2016.
26. POLAT A.A., DURGAÇ C., KAMILOĞLU Ö. The effects of indole butyric acid (IBA) on rooting of wood cuttings of can plums in open air. MKU J. Agricultural Faculty. 5 (1/2), $1,2000$.

27. SEVIK H., CETIN M., BELKAYALI N. Effects of Forests on Amounts of $\mathrm{CO}_{2}$ : Case Study of Kastamonu and Ilgaz Mountain National Parks. Pol. J. Environ. Stud. 24 (1), 253, 2015.

28. CETIN M. Consideration of permeable pavement in landscape architecture, J. Environ Prot Ecol, 16 (1), 385, 2015.

29. SEVIK H., CETIN M., KAPUCU O. Effect of light on young structures of Turkish Fir (Abies nordmanniana subsp. bornmulleriana), Oxid Commun, 39 (1-II), 485, 2016.

30. CETIN M., SEVIK H. Change of air quality in Kastamonu city in terms of particulate matter and $\mathrm{CO}_{2}$ amount. Oxid. Commun, 39 (4-II), 3394, 2016.

31. CETIN M., SEVIK H., ISINKARALAR K. Changes in the particulate matter and $\mathrm{CO}_{2}$ concentrations based on the time and weather conditions: the case of Kastamonu, Oxid. Commun, 40 (1) 2017.

32. SEVIK H., CETIN M., BELKAYALI N. Determination of characteristics factors of grafted natural varieties in Landscaping: a case study of Black Pine (Pinus Nigra) clone. Oxid Commun, 39 (3), 2820, 2016.

33. CETIN M., SEVIK H. Measuring the impact of selected plants on indoor $\mathrm{CO}_{2}$ concentrations, Pol. J .Environ. Stud., 25 (3), 973, 2016.

34. CETIN M. A change in the amount of $\mathrm{CO}_{2}$ at the center of the examination halls: case study of Turkey. Studies on EthnoMedicine 10 (2), 146, 2016.

35. CETIN M. Using GIS analysis to assess urban green space in terms of accessibility: case study in Kutahya. Int J Sust Dev World, 22 (5), 420, 2015.

36. CETIN M. Changes in the amount of chlorophyll in some plants of landscape studies. Kastamonu University, Journal of Forestry Faculty, 16 (1), 239, 2016 [In Turkish].

37. CETIN M. Evaluation of the sustainable tourism potential of a protected area for landscape planning: a case study of the ancient city of Pompeipolis in Kastamonu. Int J Sust Dev World, 22 (6), 490, 2015. 